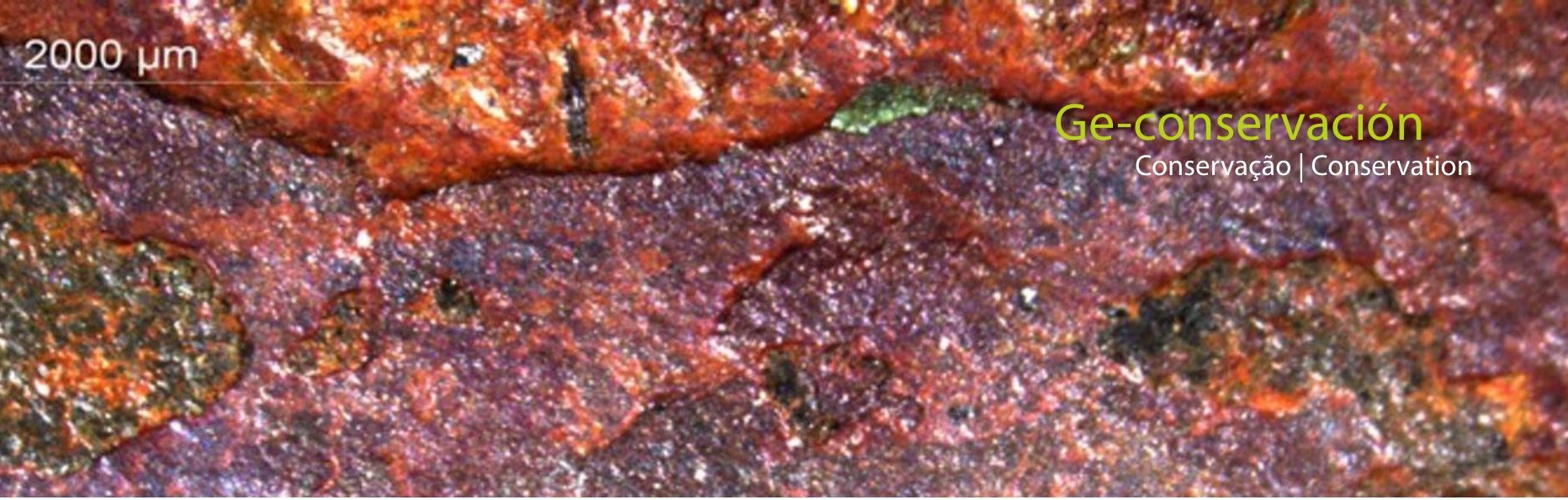

\title{
Aportación de nuevas metodologías multitécnica en el estudio y conservación de patrimonio numismático de procedencia subacuática
}

\author{
Carla Álvarez Romero, Antonio Doménech Carbó, Milagros Buendía Ortuño, Trinidad Pasíes \\ Oviedo, María Teresa Doménech Carbó
}

\begin{abstract}
Resumen: Este trabajo presenta un estudio del estado de conservación de monedas con base de cobre procedente del Museo Nacional de Arqueología Subacuática. La metodología multitécnica incluye instrumentación convencional como microscopía óptica, espectroscopia FTIR y técnicas avanzadas nanoinvasivas como voltamperometría de micropartículas y haz de iones focalizados-FESEM-EDX. Así se ha podido identificar el tipo de aleación, productos de corrosión, depósitos superficiales y antiguas intervenciones. Cabe señalar la identificación de mecanismos de alteración atípicos como la formación de complejos carboxilados de iones metálicos generados en los procesos electroquímicos de corrosión del metal o aleación y los materiales lipídicos fijados en la superficie de la moneda cuando esta estuvo en circulación y que gracias a su carácter hidrófobo se han conservado en el ambiente subacuático en el que las monedas han permanecido durante siglos. Estos hallazgos han resultado de gran utilidad para establecer los tratamientos más idóneos de conservación de estas piezas.
\end{abstract}

Palabras clave: numismática, microscopía óptica, espectroscopia FTIR, voltamperometría de micropartículas inmovilizadas, microscopía electrónica de barrido de emisión de campo con haz de iones focalizados, productos de corrosión, depósitos superficiales, antiguas intervenciones.

\section{Contribution of new multi-technical methodologies in the study and conservation of numismatic heritage of underwater origin}

\begin{abstract}
This paper presents a study of the conservation status of copper-based coins from the National Museum of Underwater Archaeology. The multitechnical methodology includes conventional instrumentation such as optical microscopy, FTIR spectroscopy and advanced non-invasive techniques such as microparticle voltamperometry and focused ion beam -FESEM-EDX. Thus it has been possible to identify the type of alloy, corrosion products, surface deposits and old interventions. It should be noted the identification of atypical alteration mechanisms such as the formation of carboxylated complexes of metal ions generated in the electrochemical processes of corrosion of the metal or alloy and the lipid materials fixed on the surface of the coin when it was in circulation and that, due to its hydrophobic character have been preserved in the underwater environment in which the coins have remained for centuries. These findings have been very useful to establish the most suitable conservation treatments for these pieces.
\end{abstract}

Keyword: numismatics, optical microscopy, FTIR spectroscopy, immobilized microparticle voltamperometry, scanning electron emission field microscopy with focused ion beam, corrosion products, surface deposits, old interventions

\section{Contribuição de novas metodologias multitécnicas no estudo e conservação do património numismático de procedência subaquática}

Resumo: Este artigo apresenta um estudo do estado de conservação de moedas à base de cobre provenientes do Museu Nacional de Arqueologia Subaquática. A metodologia multitécnica inclui instrumentação convencional, como microscopia ótica, espectroscopia FTIR e técnicas avançadas de não invasivas, como voltamperometria de micropartículas e feixe de iões focado - FESEM-EDX. Assim, foi possível identificar o tipo de liga, produtos de corrosão, depósitos superficiais e intervenções antigas. Deve-se destacar a identificação de mecanismos atípicos de alteração, como a formação de complexos carboxílicos de iões metálicos gerados nos processos eletroquímicos 
de corrosão do metal ou liga e os materiais lipídicos fixados na superfície da moeda quando ela estava em circulação e que, devido ao seu caráter hidrofóbico, foi preservado no ambiente subaquático em que as moedas permaneceram por séculos. Estas descobertas foram muito úteis para estabelecer os tratamentos de conservação mais adequados para essas peças.

Palavras-chave: numismática, microscopia ótica, espectroscopia FTIR, voltamperometria de micropartículas imobilizadas, microscopia de campo de emissão de eletrões de varrimento com feixe de íões focado, produtos de corrosão, depósitos superficiais, intervenções antigas

\section{Introducción}

Las piezas numismáticas constituyen un importante porcentaje de las colecciones de numerosos museos y del patrimonio metálico en general, además, se tratan de vestigios arqueológicos e históricos fundamentales para el estudio de diferentes aspectos de las sociedades pasadas llegando a proporcionar información, tan diversa que abarca desde la composición de las aleaciones o las técnicas empleadas para su fabricación hasta, por ejemplo, las relaciones comerciales existentes entre las diferentes ciudades en un determinado momento histórico (Álvarez Romero et al., 2016: 157).

Es en el siglo XVIII cuando comienzan a realizarse las primeras investigaciones combinando los estudios físico-químicos con los estudios arqueológicos, aunque no será hasta 1958 cuando el término de arqueometría quede acuñado gracias al Laboratorio de Investigación de Arqueología y de Historia del Arte de la Universidad de Oxford con la fundación de la revista Archaeometry (Aitken, 1961, 1970; Doménech-Carbó y Osete-Cortina, 2016: 3). En paralelo, y debido al aumento que se estaba produciendo de las colecciones de los museos más importantes del momento, comienzan a realizarse estudios sobre los procesos de deterioro de los bienes culturales, sus productos de alteración, los parámetros necesarios para su óptima conservación y el estudio de nuevas técnicas y materiales empleadas para la conservación-restauración, naciendo, de esta manera la llamada ciencia de la conservación (De Tagle, 2008: 31).

En este contexto, el empleo de estrategias multitécnica y multidisciplinares aplicadas al estudio del patrimonio ha aumentado considerablemente en los últimos años, quedando patentes los beneficios de emplearlas y la gran aportación que pueden realizar al estudio de los objetos patrimoniales.

Para el desarrollo de este trabajo se ha empleado la microscopía óptica, la voltamperometría de micropartículas inmovilizadas (VIMP), la espectroscopia infrarroja por transformada de Fourier (FTIR) y la microscopía electrónica de barrido de emisión de campo con haz de iones focalizados y microanálisis de rayos $X$ (FIB-FESEM-EDX). Dichas técnicas complementarias, han proporcionado información de las muestras de diferente naturaleza.

Las técnicas microscópicas aportan información morfológica, topográfica y textural de los objetos metálicos mediante el examen directo (DoménechCarbó et al., 2009: 23-24; Prous y del Egido, 2008: 68; Dillmann et al., 2013: 62). A través de la microscopía óptica se han podido obtener imágenes aumentadas de las piezas numismáticas e información preliminar sobre la superficie de las monedas debido a la gran diferencia tonal que exhiben los productos de corrosión del cobre y los depósitos exógenos, siendo posible realizar una primera identificación aproximativa por colores.

La voltamperometría de micropartículas inmovilizadas (VIMP) es una técnica electroquímica basada en las respuestas voltamperométricas que se producen cuando un sólido poco soluble (muestra de metal a analizar) y fijado en un electrodo inerte de grafito mediante abrasión, se sumerge en un electrolito adecuado dispuesto en la celda de un analizador voltamperométrico (DoménechCarbó, 2015: 63; Doménech-Carbó y Osete-Cortina, 2016: 86) y proporciona información sobre determinados productos de corrosión, depósitos exógenos y a su vez sobre la composición de la aleación empleada.

Por otro lado, la espectroscopia infrarroja por transformada de Fourier (FTIR) se basa en la interacción que se produce entre la radiación electromagnética infrarroja y las moléculas que componen la muestra analizada. Estas transiciones a modos vibracionales específicos son características de dichos grupos de átomos o grupos funcionales, y tienen lugar a valores de longitud de onda (o número de onda, $\mathrm{cm}^{-1}$ ) específicos pudiendo, de esta manera, caracterizar las diferentes moléculas que componen la muestra (García Rodríguez et al., 2010: 45-46). Esta técnica es ampliamente usada en los análisis de patrimonio cultural, ya que proporciona información analítica relativa tanto a materiales orgánicos como inorgánicos (Doménech-Carbó y Osete-Cortina, 2016: 63-66). Gracias a esta técnica, además de poder identificar los depósitos superficiales y los productos de corrosión presentes en las monedas de carácter inorgánico, se ha podido realizar la caracterización de diferentes productos orgánicos empleados en antiguas intervenciones de las piezas. 
La microscopía electrónica de barrido de emisión de campo con haz de iones focalizados y microanálisis de rayos $X$ (FIB-FESEM-EDX) permite obtener imágenes de gran resolución y profundidad de campo, realizar secciones transversales o trincheras gracias a la columna de iones de $\mathrm{Ga}^{+}$focalizados, que al interactuar con las muestras permite romper los enlaces químicos e ionizar los átomos de una manera controlada, y se puede obtener la composición elemental de la muestra analizada de forma cualitativa y cuantitativa gracias al microanálisis de rayos X (Álvarez Romero y Doménech Carbó, 2016 y 2017). Esta técnica analítica ya se ha empleado para el análisis de diferentes colecciones numismáticas (Doménech-Carbó et al., 2017; Álvarez-Romero et al., 2017; DoménechCarbó et al., 2019) quedando patente su capacidad para obtener información tanto de las capas más superficiales de las monedas compuestas, mayoritariamente, por productos de corrosión de los metales empleados en la fabricación de las piezas, depósitos exógenos y, como se presenta en este estudio, productos empleados en antiguas intervenciones.

\section{Objeto de estudio}

La selección de monedas de la colección numismática del Museo Nacional de Arqueología Subacuática (MNAS) consta de dieciséis monedas acuñadas en diversos momentos históricos y recuperadas en varios yacimientos subacuáticos. Todas las monedas de la selección fueron fabricadas en distintas aleaciones de cobre, lo que, unido a su procedencia, presenta depósitos exógenos y productos de corrosión característicos.

La documentación de las monedas comenzó con la consulta en Domus *(sistema informatizado de documentación y gestión museográfica) de la información relativa a cada una de las monedas; y sólo tres de las monedas (1, 6 y 16) habían recibido algún tipo de tratamiento conservativorestaurativo según dichas fichas.

La tabla 1 resume las principales características de las monedas del Museo Nacional de Arqueología Subacuática. Se identifican las piezas numismáticas estudiadas aportando datos como el yacimiento del que proceden, el emisor, la cronología, la denominación de valor, la ceca, los tipos y leyendas de anverso y reverso, datos técnicos como el peso y las dimensiones del módulo y si las piezas han sido sometidas a algún tipo de intervención conservativa-restaurativa según la documentación consultada. La figura 1 muestra las fotografías de anverso y reverso de cada una de las monedas estudiadas.

\section{Metodología analítica}

Los análisis realizados en la selección de monedas del MNAS han sido llevados a cabo en el Laboratorio de
Análisis Físico-Químico y Medioambiental de Obras de Arte (LAFQYM) del Instituto Universitario de Restauración del Patrimonio (IRP) de la Universitat Politècnica de València (UPV), el Servicio de Microscopía Electrónica de la UPV y en el departamento de Química Analítica de la Universitat de València (UV).

Para realizar la caracterización morfológica de las monedas y los productos de corrosión presentes en dichas piezas se ha empleado un microscopio óptico estereoscópico Leica S8APO (10x-80x). Los objetos numismáticos se observaron y fotografiaron digitalmente con una cámara Leica Digital FireWire Camera (DFC), controlada mediante un software Leica Application Suite (LAS). No fue necesaria la toma de muestra, ya que las monedas pudieron ser observadas directamente sin realizar ningún tipo de montaje.

Los experimentos voltamperométricos se realizaron a 298K con un potenciostato $\mathrm{CH} 1660 \mathrm{C}$ (Cambria Scientific, Llwynhendy, Llanelli, Reino Unido) con una celda electroquímica de tres electrodos: electrodo de referencia $\mathrm{Ag} / \mathrm{AgCl}$ (3 $\mathrm{M} \mathrm{NaCl}$ ), electrodo auxiliar de platino y electrodo de trabajo de grafito parafinado comercial de la marca Faber Castell, HB de $2 \mathrm{~mm}$ de diámetro sobre el que se depositaron por abrasión micropartículas de las capas de corrosión de las monedas. Como electrolito se empleó un tampón acético/acetato (Panreac) a 0,25 M y un $\mathrm{pH}$ de 4,75 sin desoxigenación para así poder emplear las mismas condiciones en el análisis de todas las muestras.

Los espectros de absorción IR fueron obtenidos en modo FTIR-ATR (reflectancia total atenuada) mediante un espectrómetro Vertex70 con un accesorio de reflectancia total atenuada (ATR) MKII Golden Gate. EI sistema de detección utilizado incluye un dispositivo con recubrimiento para estabilización de temperatura FR-DTGS (fast recovery deuterated triglycine sulphate). Las muestras son depositadas en la ventana de análisis pulverizadas y posteriormente se obtienen los espectros de cada una de ellas. Cada espectro se adquirió con un total de 32 scans o barridos y una resolución de $4 \mathrm{~cm}^{-1}$ y se procesaron con el software OPUS/IR 7.2. La toma de muestras se realizó bajo el microscopio óptico, donde se seleccionó la zona más interesante para el análisis, y mediante bisturí se obtuvieron las partículas, del orden de $\mu \mathrm{g}$, que posteriormente se depositaron en la cámara portamuestras del instrumento para proceder a su análisis.

Los análisis realizados mediante microscopía electrónica de barrido de emisión de campo con haz de iones focalizados y microanálisis de rayos $X$ se han llevado a cado con un equipo FESEM-FIB-EDX Zeiss (Orsay Physics Kleindiek Oxford Instruments) modelo AURIGA Compact que dispone de una columna FIB que opera a $30 \mathrm{kV}$ con corrientes de intensidad de $500 \mu \mathrm{A}$ y $20 \mathrm{nA}$, fino y grueso, respectivamente, para generar sendos haces de 
Tabla 1.- Principales características de las monedas analizadas y pertenecientes al Museo Nacional de Arqueología Subacuática

\begin{tabular}{|c|c|c|c|c|c|c|c|c|}
\hline Ref. & Pecio & Emisor & Cronología & Anverso & Reverso & Peso (g) & $\begin{array}{l}\text { Módulo } \\
\text { (mm) }\end{array}$ & Tratada \\
\hline 1 & $\begin{array}{c}\text { Puerto de Mazarrón, } \\
\text { Mazarrón }\end{array}$ & & Desconocida & Frustra & Frustra & 5,86 & 22,45 & \\
\hline 2 & $\begin{array}{c}\text { Puerto de Mazarrón, } \\
\text { Mazarrón }\end{array}$ & & Desconocida & $\begin{array}{c}\text { Cabeza } \\
\text { masculina a } \\
\text { derechas }\end{array}$ & Frustra & 3,91 & 20,13 & $\mathrm{x}$ \\
\hline 3 & $\begin{array}{c}\text { Puerto de Mazarrón, } \\
\text { Mazarrón }\end{array}$ & & Desconocida & Frustra & Frustra & 1,77 & 17,38 & $\mathrm{x}$ \\
\hline 4 & $\begin{array}{c}\text { Puerto de Mazarrón, } \\
\text { Mazarrón }\end{array}$ & & Desconocida & Frustra & Frustra & 2,08 & 17,77 & $\mathrm{x}$ \\
\hline 5 & $\begin{array}{c}\text { Puerto de Mazarrón, } \\
\text { Mazarrón }\end{array}$ & & Desconocida & Frustra & Frustra & 0,81 & 15,87 & $\mathrm{x}$ \\
\hline 6 & Escombreras, Cartagena & & Desconocida & Frustra & Frustra & 25,25 & 35,95 & \\
\hline 7 & $\begin{array}{c}\text { Puerto de Mazarrón, } \\
\text { Mazarrón }\end{array}$ & & Fenicia & Frustra & Frustra & 14,08 & 27,17 & $\mathrm{x}$ \\
\hline 8 & Escombreras, Cartagena & & 150-101 a.C. & Espiga de trigo & $\begin{array}{l}\text { ILIPENSE } \\
\text { Pez a } \\
\text { derechas } \\
\text { con leyenda } \\
\text { abajo entre } \\
\text { líneas }\end{array}$ & 9,57 & 27,03 & $x$ \\
\hline 9 & Isla del Fraile, Águilas & & Romana & Frustra & Frustra & 1,44 & 13,26 & $\mathrm{x}$ \\
\hline 10 & Isla del Fraile, Águilas & & Romana & Frustra & Frustra & 1,44 & 13,26 & $x$ \\
\hline 11 & Isla del Fraile, Águilas & & Romana & Frustra & Frustra & 1,02 & 14,14 & $x$ \\
\hline 12 & Isla del Fraile, Águilas & & Romana & Frustra & Frustra & 1,94 & 13,84 & $x$ \\
\hline 13 & $\begin{array}{c}\text { El Mojón, San Pedro del } \\
\text { Pinatar }\end{array}$ & & $301-400$ & $\begin{array}{c}\text { Cabeza } \\
\text { masculina a } \\
\text { derechas }\end{array}$ & Frustra & 4,16 & 21,71 & $\mathrm{x}$ \\
\hline 14 & $\begin{array}{c}\text { El Mojón, San Pedro del } \\
\text { Pinatar }\end{array}$ & Constancio II & $324-361$ & $\begin{array}{c}\text { D] N } \\
\text { CONST(ANT) } \\
\text { IUS P F AUG } \\
\text { Busto a } \\
\text { derechas con } \\
\text { ínfula }\end{array}$ & $\begin{array}{c}\text { (SPEREI } \\
\text { PVBLI) CE } \\
\text { Alegoría } \\
\text { de pie con } \\
\text { una bola } \\
\text { en la mano } \\
\text { izquierda y } \\
\text { una lanza. }\end{array}$ & 0,87 & 16,10 & $x$ \\
\hline 15 & La Azohía, Cartagena & Felipe III & 1603 & Frustra & $\begin{array}{l}\text { Resello } \\
\text { redondo con } \\
\text { marca "VIII" }\end{array}$ & 6,14 & 24,50 & $x$ \\
\hline 16 & $\begin{array}{c}\text { Playa de la Isla, } \\
\text { Mazarrón }\end{array}$ & $\begin{array}{l}\text { Gobierno } \\
\text { Provisional }\end{array}$ & $1851-1900$ & $\begin{array}{c}\text { Figura } \\
\text { femenina } \\
\text { sentada dentro } \\
\text { de gráfila de } \\
\text { puntos }\end{array}$ & $\begin{array}{l}\text { León } \\
\text { sosteniendo } \\
\text { escudo sobre } \\
\text { gráfila de } \\
\text { puntos }\end{array}$ & 3,92 & 24,74 & \\
\hline
\end{tabular}




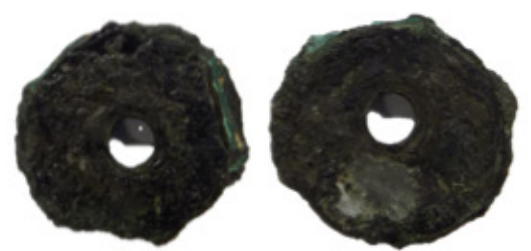

A)
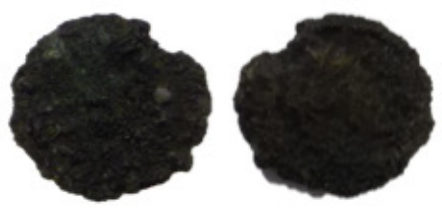

D)
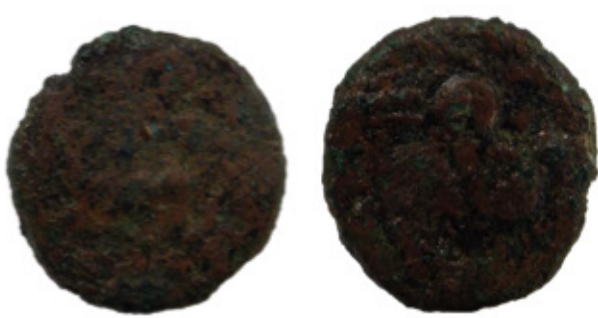

G)

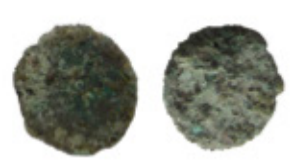

J)
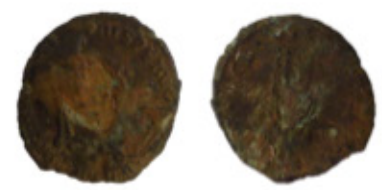

N)

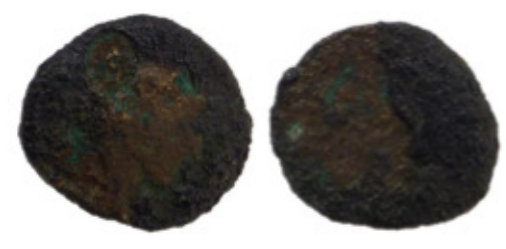

B)

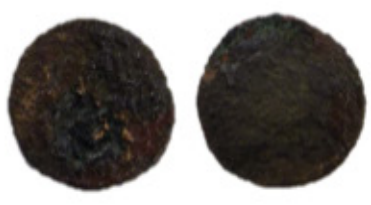

C)
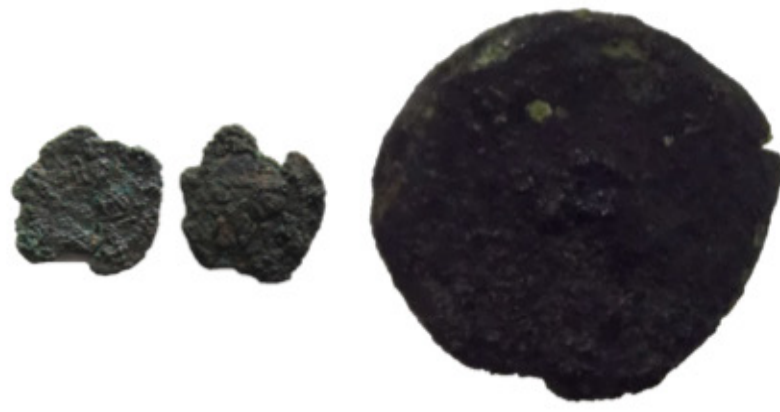

E)

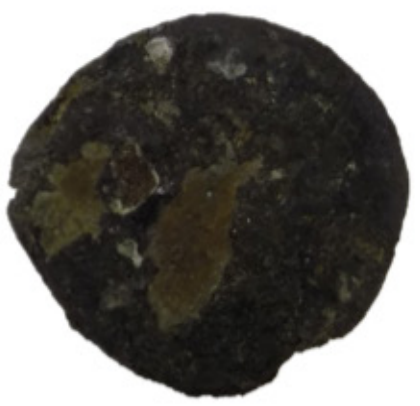

F)

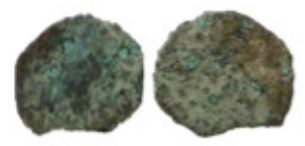

H)

I)

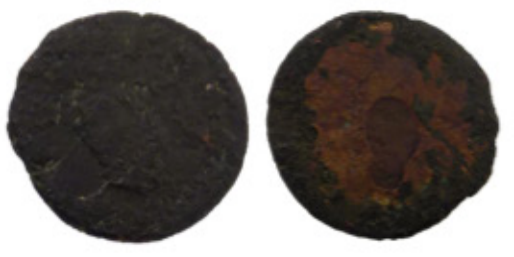

M)

L)
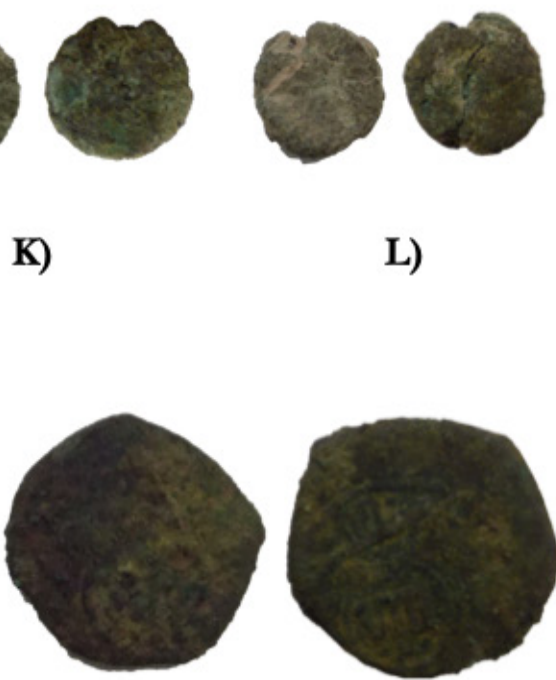

N)

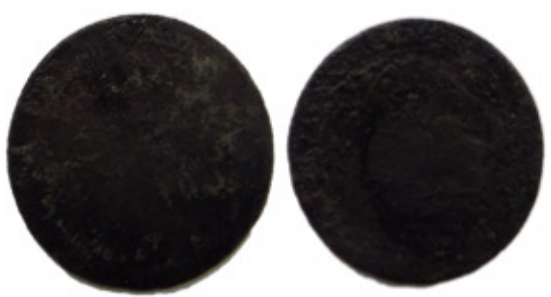

O) 
iones $\mathrm{Ga}^{+}$. Las imágenes en electrones secundarios se han obtenido aplicando un voltaje de $3 \mathrm{kV}$ en la fuente de electrones. Los elementos presentes en las muestras se han obtenido mediante un sistema EDX Oxford-X Max controlado por un software Aztec, operando a $20 \mathrm{kV}$ y con el detector situado a 6-7 $\mathrm{mm}$ de la superficie de la muestra y con el diámetro mínimo del haz, $<5 \mathrm{~nm}$ a $30 \mathrm{kV}$. Las piezas numismáticas fueron insertadas directamente en la cámara de alto vacío del microscopio sin necesidad de ningún tipo de preparación, ya que al ser metálicas poseen una buena conductividad eléctrica y no se producen efectos de acumulación de carga. El montaje de la moneda en el portamuestras se realiza con cinta de carbono de doble cara, asegurándose de que una vez insertadas en la cámara de vacío cuando se realizan los movimientos en las direcciones " $x$ ", " $y$ " $y$ " $z$ ", no se produzcan movimientos de la pieza.

\section{Resultados y discusión}

\section{-Caracterización micromorfológica}

\section{Microscopía óptica}

Con las microfotografías obtenidas a partir del microscopio óptico se ha podido hacer una aproximación visual y preliminar de los elementos que componen la capa más superficial de las monedas. En ellas se pueden observar tanto depósitos exógenos adheridos como los productos de corrosión característicos de las aleaciones empleadas para la realización de los cospeles que posteriormente fueron acuñados, que, en este caso, todas fueron realizadas en aleaciones de base cobre. El examen microscópico permite conocer, de manera no invasiva, la morfología microcristalina que presentan las capas más superficiales de las monedas y sus productos de corrosión.

\section{-Óxidos de cobre}

Los óxidos de cobre son productos de corrosión que se encuentran con frecuencia en los objetos metálicos fabricados con cobre y suelen formar pátinas estables y protectoras. Los más comunes son la cuprita y la tenorita. La cuprita $\left(\mathrm{Cu}_{2} \mathrm{O}\right)$ es un óxido cuproso (I) de color rojo, rojo-anaranjado e incluso morado, ya que varía de color en función de las impurezas y el tamaño de las partículas que la componen. Normalmente conforma la primera capa o capa más interna de corrosión (Díaz Martínez y García Alonso, 2011: 14-17; Scott, 1997; 2002). En las monedas 2, $3,7,13$ y 14 se puede observar el óxido cuproso, aunque es principalmente en la moneda 13 [figura 2A] donde se puede apreciar una mayor concentración de esta pátina de color rojizo. La tenorita (CuO) es un óxido cúprico (II) de color negro. Su formación se inicia a partir de la cuprita en un proceso secundario (Díaz Martínez y García Alonso, 2011: 17; Scott, 1997; 2002). La mayoría de las monedas estudiadas presentan esta pátina, pero es en la moneda 8 [figura 2B] donde mejor se puede apreciar y diferenciar.
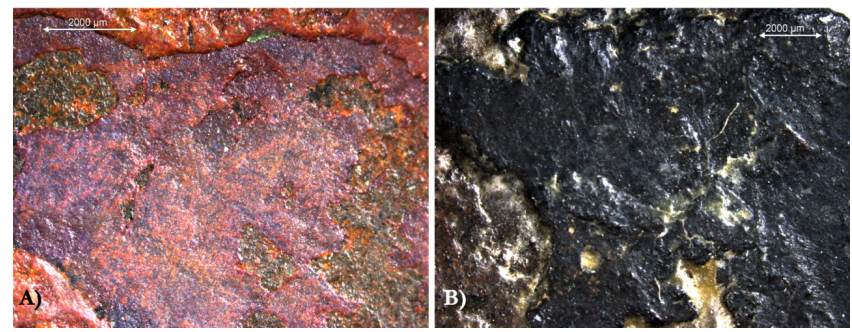

Figura 2.- Microfotografías del anverso de las monedas A) 13 (X16) y B) 8 (X10).

\section{-Cloruros e hidroxicloruros de cobre}

Los cloruros e hidroxicloruros de cobre son productos de corrosión muy inestables y suponen uno de los mayores problemas para la estabilidad de las piezas. Tienen un color verde variable y no es posible realizar una diferenciación entre ellos, a no ser que se recurra a técnicas analíticas más avanzadas, ya que muchos de ellos como los trihidroxicloruros de cobre atacamita, paratacamita o clinoatacamita, son minerales polimorfos que comparten fórmula química (Díaz Martínez y García Alonso, 2011: 24-25; Scott, 2000; 2002). En la figura 3 se pueden apreciar dos microfotografías donde están presentes estos productos de corrosión correspondientes a las monedas 3 [figura 3.A] y 9 [figura 3.B], aunque se han podido identificar en la mayoría de las monedas salvo en las piezas 8, 13 y 16 (está última intervenida según la documentación del Museo mediante electrólisis y sesquicarbonato de sodio, lo que podría explicar el por qué no se han encontrado cloruros).

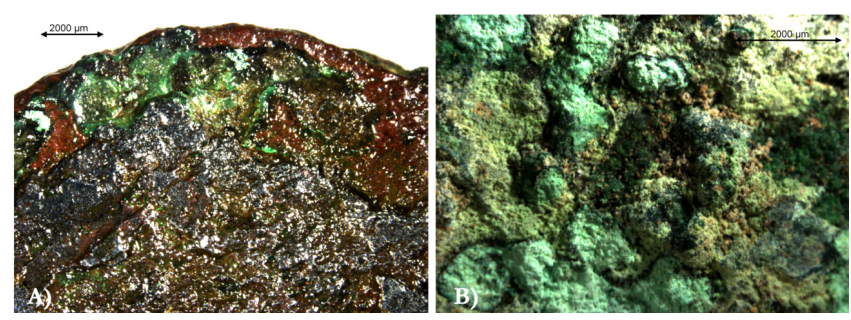

Figura 3.- Microfotografías del anverso de las monedas A) 3 (X10) y B) 9 (X16).

\section{-Elementos exógenos}

Además de los productos de corrosión procedentes de la alteración de la aleación de cobre con la que fueron fabricadas las monedas, la microscopía óptica permite reconocer distintos materiales exógenos que se han depositado o adherido a la superficie original de las piezas. En la microfotografía correspondiente a la moneda 12 [figura 4A] se pueden observar depósitos de materia de color marrón que podrían asociarse a minerales silíceos y arcillosos procedentes del lecho marino donde la moneda 
estuvo hasta que se recuperó y que posteriormente han sido caracterizados gracias a la espectroscopia FTIR (monedas 1 y 6-16). En las fotografías también se pueden apreciar las evidencias que han dejado los diferentes tratamientos aplicados en las monedas, como sucede en la fotografía de la moneda 16 [figura 4B], donde se observa cómo toda la superficie de la moneda se encuentra recubierta de una película de naturaleza orgánica y aspecto translúcido brillante.
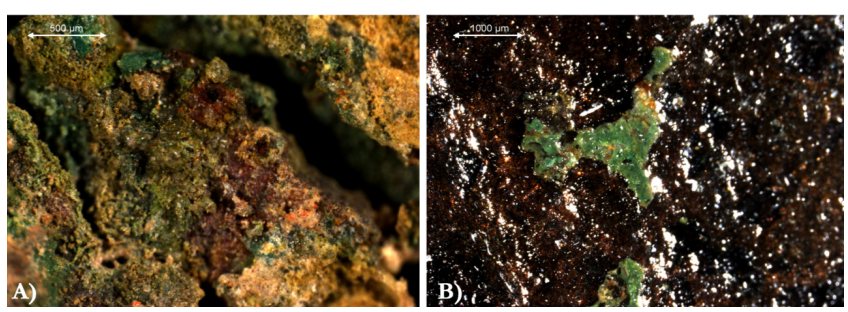

Figura 4.- Microfotografías del anverso de las monedas A) 12 (X50) y B) 16 (X25).

\section{-Identificación de productos de corrosión y consolidantes utilizados en intervenciones previas}

\section{VIMP}

Gracias a los análisis realizados mediante VIMP se ha podido identificar la presencia de cuprita, tenorita, atacamita, sales de $\mathrm{Pb}, \mathrm{HgS}$ y $\mathrm{CdS}$.

En la figura 5 se pueden observar, a título de ejemplo, diferentes voltamperogramas obtenidos para las muestras de las monedas analizadas. En la figura 5.A, se muestra el voltamperograma correspondiente a la moneda 1, se puede distinguir un pico catódico a - $-0,25 \mathrm{~V}$, que puede atribuirse a la reducción de atacamita a cobre metálico. La intensa señal catódica a $-0,95 \mathrm{~V}$ corresponde a la reducción de tenorita a cobre metálico, que acompaña a la reducción de cuprita. Esta señal conjunta aparece en las monedas 1-5, 7, 9-12 y 15, lo que indica que en estas piezas se pueden encontrar los dos óxidos de cobre,
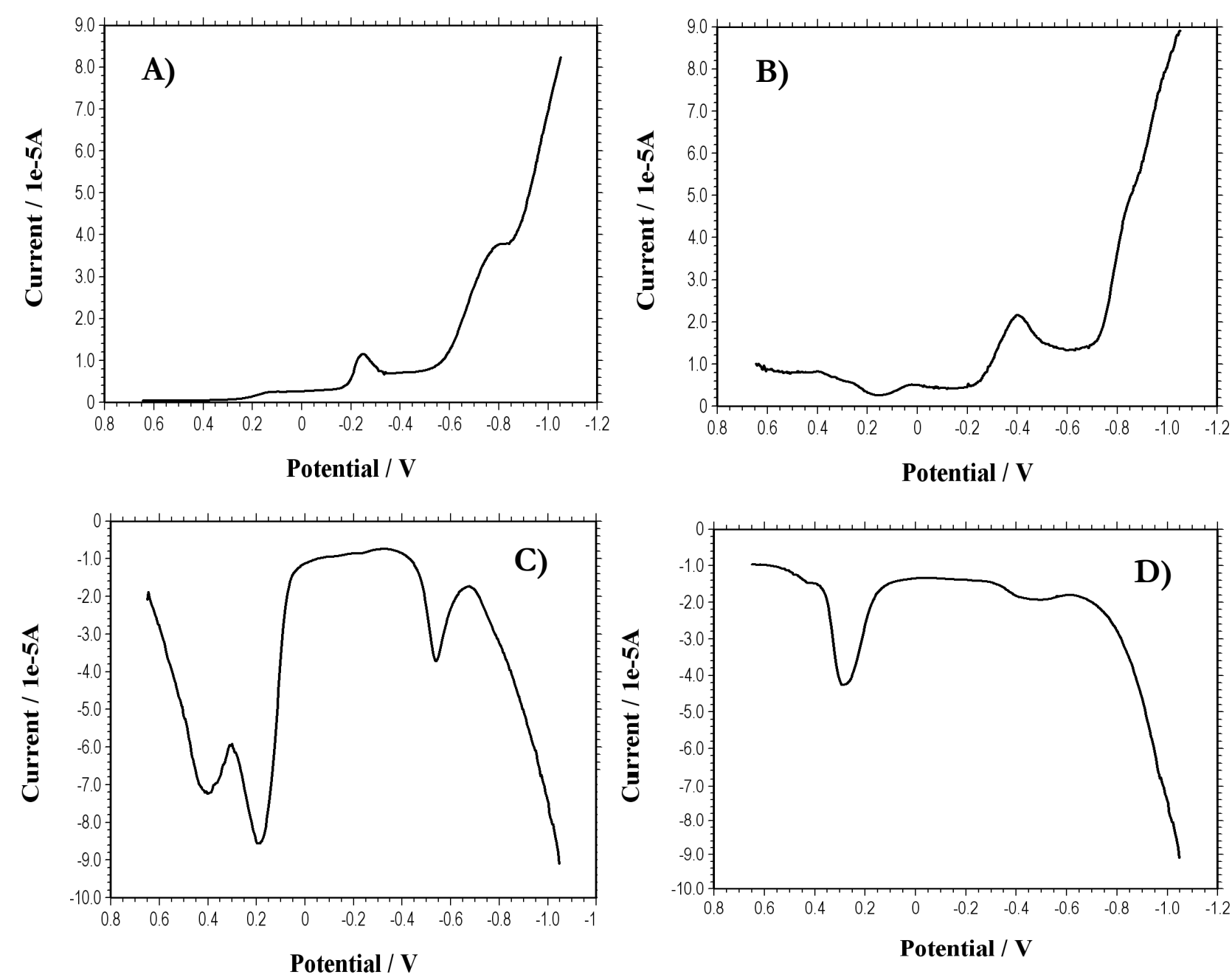

Figura 5.- Voltamperogramas de onda cuadrada de las muestras tomadas en las monedas del Museo Nacional de Arqueología Subacuática: A) 1; B y C) 8 y D) 4 
mientras que en las monedas 6, 8, 13 y 14 únicamente se puede observar la señal de cuprita a 0,10V. Por último, también es destacable que en alguna de las piezas se han podido encontrar peculiaridades, como en la moneda 8 [figura 5.B y 5.C], donde se analizó una región de color amarillo y cuyos voltamperogramas muestran un perfil catódico con la señal de atacamita a -0,25V acompañada de un pico más elevado a $-0,35 \mathrm{~V}$ y aparecen picos anódicos intensos a -0,35 y -0,20V, que podría asociarse a sulfuro de cadmio (SCd) (Ortiz-Miranda et al., 2016), o en la moneda 4 [figura 5.D], donde las señales anódicas a 0,20V y 0,45V apuntan a la presencia de sulfuro de mercurio ( $\mathrm{HgS}$ ) (Doménech-Carbó et al., 2012). Estos depósitos exógenos poco comunes pueden estar asociados a la intensa actividad minera de la zona costera donde se encuentran los pecios donde fueron halladas las monedas.

\section{Espectroscopia FTIR}

La tabla 2 resume el conjunto de compuestos identificados mediante espectroscopia FTIR en la colección de monedas procedente del Museo Nacional de Arqueología Subacuática.

Dentro de los compuestos inorgánicos se han podido reconocer tres tipos de carbonatos, dos carbonatos de calcio, y un carbonato de plomo. Los carbonatos de calcio identificados han sido el aragonito y la calcita (Gunasekaran et al., 2006. Estos dos compuestos comparten la misma fórmula química $\mathrm{CaCO}_{3}$, pero se pueden diferenciar debido a que el sistema en el que cristalizan es diferente (el aragonito en el sistema ortorrómbico y la calcita en el sistema hexagonal (Hurlbut y Klein, 1992: 316) y a que las bandas IR que emiten también son diferentes, gracias a lo cual es posible su discriminación mediante FTIR. La calcita se encuentra en la naturaleza con mayor facilidad, puede encontrarse en rocas calizas, en margas o areniscas y formarse por la evaporación de aguas calcáreas (Hurlbut y Klein, 1992: 319), por eso es común que en las muestras analizadas se hayan podido formar depósitos de este compuesto. Por otro lado, el aragonito es mucho menos corriente que la calcita y menos estable (Hurlbut y Klein, 1992: 325). Su formación se produce en condiciones físico-químicas muy determinadas: en entornos marinos cálidos con temperaturas medias por encima de $6 \pm 3{ }^{\circ} \mathrm{C}$ y condiciones adecuadas de salinidad donde puede verse favorecida la formación de aragonito biológico y abiológico frente a la formación de calcita (Sánchez-Beristain et al., 2016), por ejemplo, las conchas de los organismos marinos están compuestas de aragonito. El último carbonato identificado es un carbonato de plomo, la hidrocerusita $\left(2 \mathrm{PbCO}_{3} \cdot \mathrm{Pb}(\mathrm{OH})_{2}\right)$, concretamente en las muestras extraídas de las monedas 1 y 5, ambas halladas en el pecio de Puerto de Mazarrón, Murcia. Esto indica que, posiblemente, la aleación empleada para la fabricación de estas dos monedas contuviera, en mayor o menor proporción, plomo. Otros de los compuestos inorgánicos identificados en muchas de las muestras son los minerales silíceos y arcillosos los cuales es posible que procedan del lecho marino donde han estado depositadas las piezas hasta su recuperación. Los trihidroxicloruros de cobre como la atacamita y la clinoatacamita $\left(\mathrm{Cu}_{2} \mathrm{Cl}(\mathrm{OH})_{3}\right)$ son los productos de corrosión de cobre que con mayor frecuencia aparecen en los análisis de las muestras. Ambos comparten la misma formula química, pero es posible diferenciarlos tanto por el sistema en el que cristalizan, la atacamita en el sistema ortorrómbico y la clinoatacamita en el sistema monoclínico (Scott, 2000: 41; Scott, 2002: 124), como por la posición de las bandas IR, aunque es muy común que ambos compuestos coexistan y se encuentren los dos en una misma muestra. El último compuesto identificado del grupo de los inorgánicos es la whewellita, un oxalato de calcio monohidrato $\left(\mathrm{CaC}_{2} \mathrm{O}_{4} \cdot \mathrm{H}_{2} \mathrm{O}\right)$ formado debido a la degradación de la materia orgánica presente en la superficie de la moneda (Salvadó et al., 2009) o procesos biogenéticos propios del medio subacuático (Carati et al., 2003; Toffolo et al., 2019).

Los compuestos orgánicos identificados se pueden dividir en dos grupos: a) la materia orgánica que se depositó en la superficie de la moneda de manera natural y debido al uso que se ha realizado de las piezas cuando estuvieron en circulación y b) los productos relacionados con las intervenciones conservativo-restaurativas realizados en las monedas. Dentro del primer grupo se pueden incluir los complejos metálicos de tipo carboxilatos de $\mathrm{Pb}$ y $\mathrm{Cu}$, identificados en las monedas 1-6, 8 y 10, los cuales han podido formarse al combinarse los iones $\mathrm{Cu}(\mathrm{II})$ o $\mathrm{Pb}$ (II) liberados durante los procesos de corrosión electroquímica de la moneda y los ácidos grasos de cadena larga liberados mediante procesos hidrolíticos a partir de la película lipídica formada en la superficie de la moneda mientras estuvo en circulación. El segundo grupo lo constituyen la cera microcristalina y la resina acrílica, posiblemente Paraloid B72 ${ }^{\circ}$ (Derrick et al., 1999), procedentes de los procesos de conservación-restauración sufridos por las monedas, ya que estos productos son empleados con frecuencia en tratamientos de protección de objetos de cobre y bronce (Balbo et al., 2012; Álvarez Romero, 2013, 2014 y 2015). Como es posible observar en la tabla 3 en las monedas 1-6, $8,10,13$ y 16 se han identificado estos productos, por lo que, aunque en las fichas DOMUS únicamente conste que tres de las piezas de la colección han sido intervenidas, gracias a los análisis realizados se ha podido determinar que más monedas de las indicadas han sido tratadas. Por último, se ha podido determinar la presencia de materia lipídica (1, $5,13,15$ y 16) y materia orgánica inespecífica (monedas 7 , $9,10,14$ y 15), las cuales podrían estar relacionadas, bien con estos tratamientos o bien con la manipulación de las monedas realizada durante su vida útil o una vez que han sido recuperadas.

La tabla 3 resume los compuestos inorgánicos y orgánicos identificados en cada una de las muestras analizadas de la colección numismática. Además, se ha procedido a realizar una aproximación semicuantitativa en función de la intensidad de las bandas que presentaba cada uno de los compuestos identificados en los espectros. 
Tabla 2.- Compuestos con las correspondientes bandas IR y su asignación identificados en las monedas de la colección del Museo Nacional de Arqueología Subacuática

\begin{tabular}{|c|c|c|}
\hline Compuesto & Posición de la banda $\left(\mathrm{cm}^{-1}\right)$ & Asignación \\
\hline \multirow{3}{*}{$\begin{array}{l}\text { ARAGONITO } \\
\qquad\left(\mathrm{CaCO}_{3}\right)\end{array}$} & 1473 & Tensión $v_{3}$ \\
\hline & 858,843 & Tensión $\boldsymbol{v}_{2}$ \\
\hline & 712,700 & Tensión $v_{4}$ \\
\hline \multirow{3}{*}{$\begin{array}{l}\text { CALCITA } \\
\left(\mathrm{CaCO}_{3}\right)\end{array}$} & 1422 & Tensión $v_{3}$ \\
\hline & 876,848 & Tensión $v_{2}$ \\
\hline & 712 & Tensión $v_{4}$ \\
\hline \multirow{4}{*}{$\begin{array}{l}\text { HIDROCERUSITA } \\
\left(2 \mathrm{PbCO}_{3} \cdot \mathrm{Pb}(\mathrm{OH})_{2}\right)\end{array}$} & 3510,3402 & Tensión $\mathrm{OH}$ \\
\hline & 1400 & Tensión $v_{3}$ \\
\hline & 1043 & Tensión $v_{1}$ \\
\hline & 682 & Tensión $v_{4}$ \\
\hline \multirow{3}{*}{$\begin{array}{l}\text { MINERALES SILÍCEOS Y } \\
\text { ARCILLOSOS }\end{array}$} & 3694,3621 & Tensión OH \\
\hline & $1129,1020,1005,911$ & Tensión $\mathrm{SiO}$ grupo $\mathrm{SiO}_{4}$ \\
\hline & 793,753 & Doblete otz \\
\hline $\begin{array}{l}\left.\text { CUPRITA ( } \mathrm{Cu}_{2} \mathrm{O}\right) \\
\text { TENORITA (CuO) }\end{array}$ & $650-500$ & Tensión \\
\hline \multirow{2}{*}{$\begin{array}{l}\text { ATACAMITA } \\
\left(\mathrm{Cu}_{2} \mathrm{Cl}(\mathrm{OH})_{3}\right)\end{array}$} & $3438,3357,3330$ & Tensión $\mathrm{OH}$ \\
\hline & $950,890,845$ & Deformación $\mathrm{OH}$ \\
\hline \multirow{2}{*}{$\begin{array}{l}\text { CLINOATACAMITA } \\
\left(\mathrm{Cu}_{2} \mathrm{Cl}(\mathrm{OH})_{3}\right)\end{array}$} & $3444,3359,3310$ & Tensión $\mathrm{OH}$ \\
\hline & $921,904,891,863,827$ & Deformación $\mathrm{OH}$ \\
\hline \multirow{2}{*}{$\begin{array}{l}\text { WHEWELLITA } \\
\left(\mathrm{CaC}_{2} \mathrm{O}_{4} \cdot \mathrm{H}_{2} \mathrm{O}\right)\end{array}$} & 1643 & $\begin{array}{c}\text { Tensión asimétrica - } \\
\text { COO }\end{array}$ \\
\hline & 1322 & $\begin{array}{c}\text { Tensión simétrica - } \\
\text { COO }\end{array}$ \\
\hline \multirow{5}{*}{ CARBOXILATOS Pb } & $2955,2919,2849$ & $\begin{array}{l}\text { Tensión } \mathrm{CH} \text { grupos } \\
\text { metilenos y metilos }\end{array}$ \\
\hline & 1540,1513 & $\begin{array}{c}\text { Tensión asimétrica } \\
\mathrm{COO}^{-}\end{array}$ \\
\hline & 1472,1462 & Flexión $\mathrm{CH}_{2}$ \\
\hline & 1419 & $\begin{array}{c}\text { Tensión simétrica } \\
\mathrm{COO}^{-}\end{array}$ \\
\hline & $1350-1180$ & Deformación $\mathrm{CH}_{2}$ \\
\hline \multirow{3}{*}{ CARBOXILATOS Cu } & 1585 & $\begin{array}{l}\text { Tensión asimétrica } \\
\mathrm{COO}^{-}\end{array}$ \\
\hline & 1411 & $\begin{array}{c}\text { Tensión simétrica } \\
\mathrm{COO}^{-}\end{array}$ \\
\hline & 1470 & Deformación $\mathrm{CH}_{2}$ \\
\hline \multirow{2}{*}{$\begin{array}{l}\text { MATERIA ORGÁNICA } \\
\text { INESPECÍFICA }\end{array}$} & $2950-20$ & $\begin{array}{c}\text { Tensión asimétrica } \mathrm{CH}_{2} \\
\text { y CH}\end{array}$ \\
\hline & $2855-35$ & $\begin{array}{c}\text { Tensión simétrica } \mathrm{CH}_{2} \mathrm{y} \\
\mathrm{CH}_{3}\end{array}$ \\
\hline \multirow{3}{*}{ CERA MICROCRIS TALINA } & $2951,2915,2845$ & Tensión C-H \\
\hline & $1471,1462,1372$ & Flexión C-H \\
\hline & 728,719 & Torsión C-H \\
\hline \multirow{5}{*}{ MATERIA LIPÍDICA } & $2948,2920,2850$ & Tensión C-H \\
\hline & 1738,1704 & Tensión $C=0$ \\
\hline & $1472,1468,1379$ & Flexión C-H \\
\hline & 1178 & Tensión C-O \\
\hline & 736,727 & Torsión C-H \\
\hline \multirow{4}{*}{ RESINA ACRÍLICA } & $2964,2929,2829$ & Tensión C-H \\
\hline & 1716 & Tensión $C=0$ \\
\hline & $1465,1440,1380,1359$ & Flexión C-H \\
\hline & $\begin{array}{c}1247,1228,1151,1130,1022, \\
963\end{array}$ & Tensión C-O \\
\hline
\end{tabular}


Tabla 3.- Compuestos identificados en las muestras analizadas y clasificación semicuantitativa de cada uno de ellos mediante la leyenda: $\mathrm{x}$ bandas débiles, $\mathrm{xx}$ bandas moderadas y $\mathrm{xxx}$ bandas muy intensas

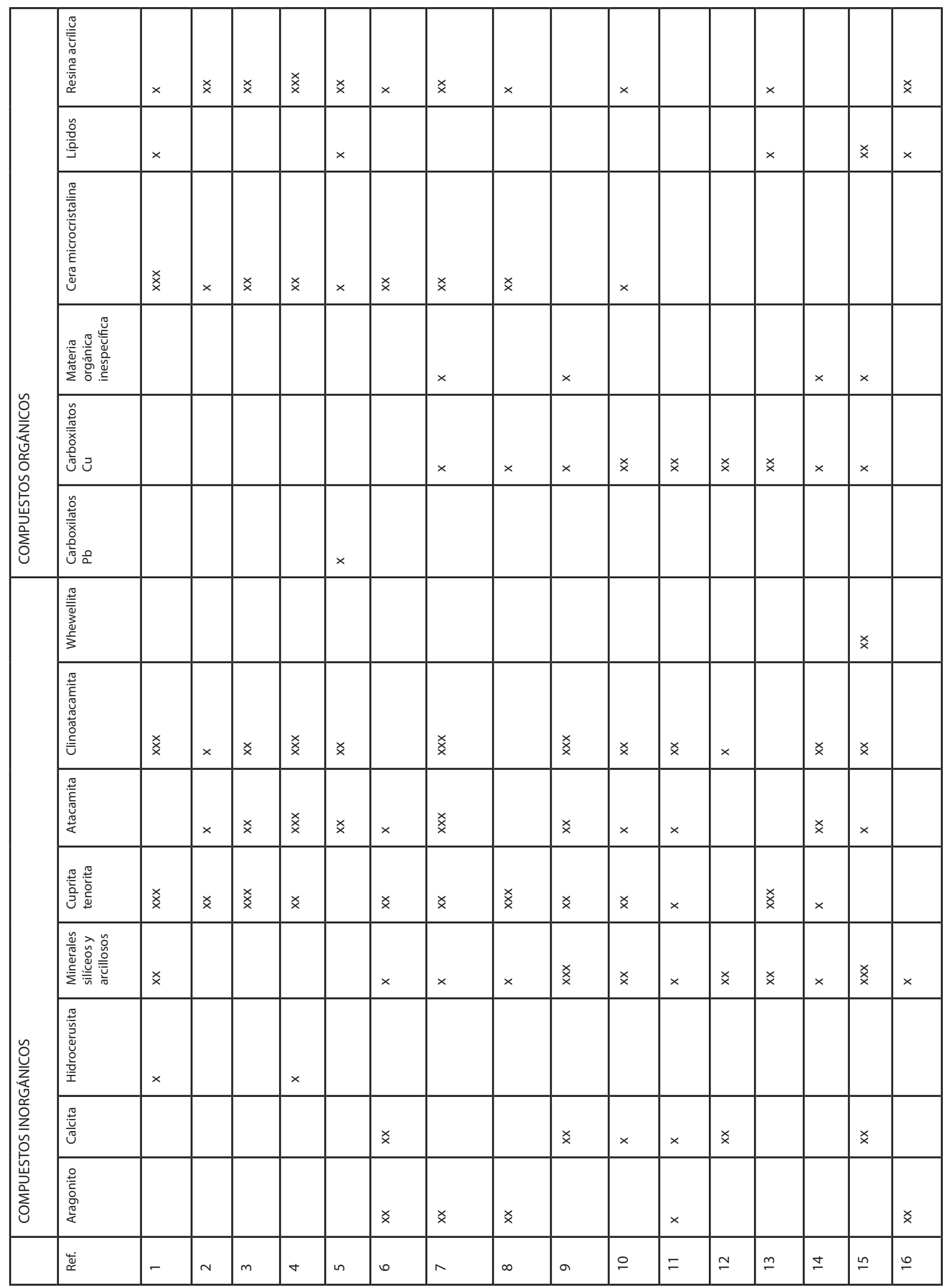




\section{FESEM-EDX}

Debido al delicado estado de conservación de la mayoría de las monedas que conforman la colección, únicamente se pudieron analizar mediante FIB-FESEM-EDX las dos monedas que presentaban un buen estado de conservación y una gran cohesión. En el resto de las monedas se desestimó este análisis ya que las muestras han de ser adheridas al portamuestras mediante cinta adhesiva que podría producir su fragmentación dada su fragilidad.

En la figura 6.A se puede observar la trinchera realizada en la moneda 7 . Se puede apreciar una capa superficial de unos $2 \mu \mathrm{m}$ de espesor correspondiente a la película protectora aplicada durante los tratamientos conservativosrestaurativos que se habrían realizado en la pieza tras su hallazgo. Esta película se ha caracterizado como una resina acrílica mediante los análisis de FTIR que recubre toda la moneda. El microanálisis de rayos $X$ ha permitido detectar $\mathrm{C}, \mathrm{O}$, Sn y Pb en esta capa acrílica. La presencia de $\mathrm{Sn}$ y $\mathrm{Pb}$ en esta zona se asocia a una migración de estos elementos hacia el exterior con posible formación de complejos metálicos carboxilados. Por debajo de esta primera capa, y con un espesor de unos $4 \mu \mathrm{m}$, es apreciable la capa de corrosión, donde se pueden observar microporos, microfisuras y zonas donde se ha producido la infiltración del material sintético empleado para actuar de capa protectora y consolidante. En esta zona se han identificado elementos exógenos a la moneda como $\mathrm{C}, \mathrm{O}, \mathrm{Si}, \mathrm{P}$ y $\mathrm{Cl}$. El núcleo metálico de la moneda es inapreciable, por lo que se puede deducir que se encontraría a más profundidad que la que posee la trinchera realizada, aunque si es posible deducir que esta moneda se realizó con una aleación de $\mathrm{Cu}$, $\mathrm{Sn}$ y Pb, ya que son los elementos identificados en la capa de corrosión accesible con la trinchera.

La figura 6.B muestra la trinchera realizada en la moneda 15. Como se puede observar en la imagen la muestra presenta una capa superficial que correspondería a la capa corrosión, en la que mediante EDX se ha identificado $\mathrm{C}, \mathrm{O}, \mathrm{Mg}, \mathrm{Al}, \mathrm{Si}, \mathrm{P}$, $\mathrm{Cl}, \mathrm{K}, \mathrm{Ca}$ y Fe. Son perceptibles, a unos $2 \mu \mathrm{m}$ de profundidad, numerosas microfisuras, por donde han podido penetrar elementos químicos exógenos a la moneda hacia el interior. El núcleo metálico de la pieza no es perceptible, ya que se encontraría a mayor profundidad de la obtenida con la trinchera. Debido a la condición de bien cultural del objeto no ha sido posible profundizar más, pero en la zona más profunda de la trinchera únicamente se ha podido identificar $\mathrm{Cu}$, por lo que esta moneda se habría fabricado en este metal principalmente.

\section{Conclusiones}

La aproximación multitécnica puesta a punto permite realizar estudios exhaustivos de colecciones numismáticas y conocer diferentes aspectos de su naturaleza y de la historia corrosiva, deposicional y conservativa-restaurativa que han sufrido las piezas de un modo micro y nanoinvasivo.

Gracias a los resultados obtenidos se ha podido realizar una aproximación a la composición de la capa más superficial de monedas de procedencia subacuática. Se han podido identificar tanto compuestos inorgánicos y orgánicos de naturaleza endógena y exógena, como pueden ser los productos de corrosión del cobre, los carbonatos de calcio, la materia lipídica depositada cuando la moneda estuvo en circulación o la resina acrílica y las ceras utilizadas en intervenciones de conservación-restauración anteriores. Además, se ha podido establecer que muchas de las monedas de las cuales no había documentación sobre los tratamientos recibidos en el Museo han sido intervenidas ya que muestran bandas características de los productos empleados para estos fines. Esto será de gran utilidad para establecer el tratamiento de conservación más adecuado en el futuro.

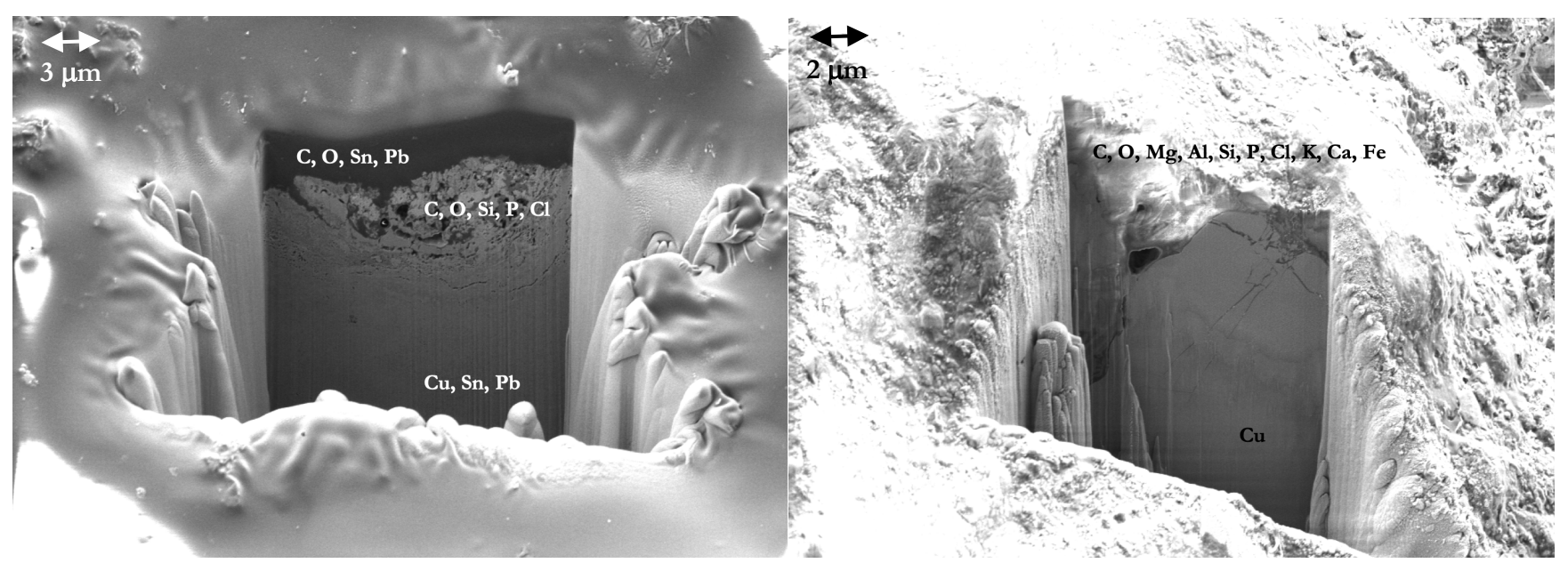

Figura 6.- . Imágenes obtenidas mediante FIB-FESEM de las microtrincheras realizadas en las monedas A) 7 y B) 15. Puede apreciarse la diferencia textural en las capas más externas de las trincheras donde se observan productos de corrosión y productos de intervenciones previas y el facetado del metal de la región más profunda. 


\section{Agradecimientos}

La presente investigación está financiada con los proyectos I+D: CTQ2017-85317-C2-1-P y CTQ2014-53736-C3 cofinanciado por el Ministerio de Ciencia, Innovación y Universidades, el Fondo Europeo de Desarrollo Regional (ERDF) y la Agencia Estatal de Investigación (AEI). Los autores agradecen al Museo Nacional de Arqueología Subacuática, a la Dirección General de Bienes Culturales de la Comunidad Autónoma de la Región de Murcia y la colaboración de Manuel Planes, José Luis Moya y Alicia Nuez, técnicos del Servicio de Microscopía Electrónica de la Universitat Politècnica de València.

\section{Bibliografía}

AITKEN, M. J. (1961): Physics and Archaeology. New York, Interscience.

AITKEN, M. J. (1970): "Publication of Archaeometry", Antiquity, 44, 173: 60.

ÁLVAREZ ROMERO, C. (2013, 2014 Y 2015): “La conservación de objetos metálicos", Arché: Publicación del Instituto Universitario de Restauración del Patrimonio de la UPV, 8, 9 y 10: 219-232.

ÁLVAREZ ROMERO, C; DOMÉNECH CARBÓ, M.T., MARTÍNEZ BAZÁN, M.L.; PASÍES OVIEDO, T.; BUENDÍA ORTUÑO, M.; DOMÉNECH CARBÓ, A. (2016): "Aportación de las técnicas de microscopía electrónica y nanoelectroquímicas al estudio histórico de una colección numismática" en Emerge 2016. Jornadas de Investigación Emergente en Conservación y Restauración de Patrimonio, 157-164.

ÁLVAREZ-ROMERO, C; DOMÉNECH CARBÓ, M.T. (2016 y 2017): "Aplicación de la técnica de microscopía electrónica de barrido de emisión de campo con haz de iones focalizados-microanálisis de rayos X a colecciones numismáticas", Arché. Publicación del Instituto Universitario de Restauración del Patrimonio de la UPV, 11 y 12: 65-70.

ÁLVAREZ ROMERO, C.; DOMÉNECH CARBÓ, A.; DOMÉNECH CARBÓ, M.T.; PASÍES OVIEDO, T.; BUENDÍAORTUÑO, M. (2017): “Estudio arqueométrico de maravedís de Felipe IV (1660-1664)", Sagvntvm, Papeles del Laboratorio de Arqueología de Valencia, 49: 235-239.

BALBO, A.; CHIAVARI, C.; MARTINI, C.; MONTICELLI, C. (2012): "Effectiveness of corrosion inhibitor films for the conservation of bronzes and gilded bronzes", Corrosion Science, 59: 204-212.

CARIATI, F.; RAMPAZZI, L.; TONIOLO, L.; POZZI, A. (2003): “Calcium oxalate films on Stone surfaces: experimental assessment of the chemical formation" Studies in Conservation, 45: 180-188.

DE TAGLE, A. (2008): "El papel de las ciencias en la preservación del patrimonio cultural. La situación de Europa" Bienes culturales: revista del Instituto del Patrimonio Histórico Español, 8: 27-36.

DERRICK, M.R.; STULIK, D.C.; LANDRY, J.M. (1999): Infrared Spectroscopy in Conservation Science. Los Angeles: The Getty Conservation
DÍAZ MARTÍNEZ, S.; GARCÍA ALONSO, E. (2011): Técnicas metodológicas aplicadas a la conservación-restauración del patrimonio metálico. Ministerio de Cultura, Madrid.

DILLMANN, P.; WATKINSON, D.; ANGELINI, E.; ADRIAENS, A. (Eds.) (2013): Corrosion and Conservation of Cultural Heritage Metallic Artefacts. European Federation of Corrosion Publications, Cambridge, England.

DOMÉNECH-CARBÓ, A.; DOMÉNECH-CARBÓ, M.T.; COSTA, V. (2009): Electrochemical methods in archaeometry, conservation and restauration, in Scholz, F. (Ed.) Monographs in electrochemistry. Springer, Berlin.

DOMÉNECH CARBÓ, M.T.; VÁZQUEZ DE AGREDOS-PASCUAL, M.L.; OSETE-CORTINA, L.; DOMÉNECH-CARBÓ, A.; GUASCH-FERRE, N.; MANZANILLA, L.R.; VIDAL-LORENZO, C. (2012): “Characterization of prehispanic cosmetics found in a burial of the ancient city of Teotihuacan (Mexico)", Journal of Archaeological Science, 39: 10431062.

DOMÉNECH-CARBÓ, A. (2015): "Aportaciones recientes de la Voltamperometría de micropartículas a la conservación y restauración de bienes culturales" en Proceedings of the Second European Conference on electrochemical methods applied to the conservation of artworks, Doménech-Carbó, A; Doménech-Carbó, M.T. (Eds.). Universitat Politècnica de València, Valencia.

DOMÉNECH-CARBÓ, M.T.; OSETE-CORTINA, L. (2016): “Another beauty of analytical chemistry: chemical analysis of inorganic pigments of art and archaeological objects" ChemTexts, 2: 14.

DOMÉNECH-CARBÓ, A.; DOMÉNECH-CARBÓ, M. T.; ÁLVAREZROMERO, C.; MONTOYA, N.; PASÍES-OVIEDO, T.; BUENDÍA-ORTUÑO, M. (2017): "Electrochemical characterization of coinage techniques the 17th century: The maravedís case", Electroanalysis, 29: 20082018.

DOMÉNECH-CARBÓ, M.T.; ÁLVAREZ-ROMERO, C.; DOMÉNECHCARBÓ, A.; OSETE-CORTINA, L.; MARTÍNEZ-BAZÁN, M.L. (2019): "Microchemical Surface analysis of historic copper-based coins by the combined use of FIB-FESEM-EDX, OM, FTIR spectroscopy and solid-state electrochemical techniques" Microchemical Journal, 148: 573-581.

GARCÍA RODRIGUEZ, M.A.; CHÉRCOLES ASENSIO, R.; SANZ RODRÍGUEZ, E. (2010): “Métodos analíticos desarrollados en el IPCE para el estudio de bienes culturales basados en la Espectroscopia Infrarroja por Transformada de Fourier y Técnicas Cromatográficas" en del Egido, M.; Juanes, D. (Coords.) (2010): La Ciencia y el Arte II. Ciencias experimentales y conservación del Patrimonio Histórico. Ministerio de Cultura, Madrid.

GUNASEKARAN, S.; ANBALAGAN, G.; PANDI, S. (2006): "Raman and infrared spectra of carbonates of calcite structure", Journal of Raman Spectroscopy, 37: 892-899.

HURLBUT, C.S.; KLEIN, C. (1992): Manual de mineralogía de Dana. Barcelona: Editorial Reverté, S.A. 
ORTIZ-MIRANDA, A.S.; DOMÉNECH-CARBÓ, A.; DOMÉNECHCARBÓ, M.T.; OSETE-CORTINA, L.; VALLE-ALGARRA, F.M.; BOLÍVARGALIANO, F.; MARTÍN-SÁNCHEZ, I.; LÓPEZ-MIRAS, M.M. (2016): "Electrochemical characterization of biodeterioration of paint films containing cadmium yellow pigment", Journal of Solid State Electrochemistry, 20: 3287-3302.

PROUS, S.; DEL EGIDO, M. (2008): La Ciencia y el Arte. Ciencias experimentales y conservación del Patrimonio Histórico. Instituto del Patrimonio Histórico Español, Ministerio de Cultura, España.

SALVADÓ, N.; BUTÍ, S.; NICHOLSON, J.; EMERICH, H.; LABRADOR, A.; PRADELL, T. (2009): "Identification of reaction compounds in micrometric layers from gothic paintings using combined SR-XRD and SR-FTIR", Talanta, 79: 419-428.

SÁNCHEZ-BERISTAIN， F.; GARCÍA-BERRERA， P.; CALVILLOCANADELL, L. (2016): "Mares calcíticos y aragoníticos: efectos en organismos formadores de arrecifes a través del tiempo", TIP Revista Especializada en Ciencias Químico-Biológicas, 19, 1: 45-53.

SCOTT, D.A. (1997): “Copper compounds in metals and colorants: Oxides and hydroxides" in Studies in Conservation, 42, 2: 93-100.

SCOTT, D.A. (2000): "A review of copper chlorides and related salts in bronze corrosion and painting pigments", Studies of Conservation, 45: 39-53.

SCOTT, D.A. (2002): Copper and Bronze in Art. Corrosion, colorants, conservation. Los Angeles, California: Getty Publications.

TOFFOLO, M.B.; REGEV, L.; DUBERNET, S.; LEFRAIS, Y.; BOARETTO, E. (2019): "FTIR-Based Crystallinity Assessment of Aragonite-Calcite Mixtures in Archaeological Lime Binders Altered by Diagenesis", Minerals, 9, 121.

\section{Autor/es}

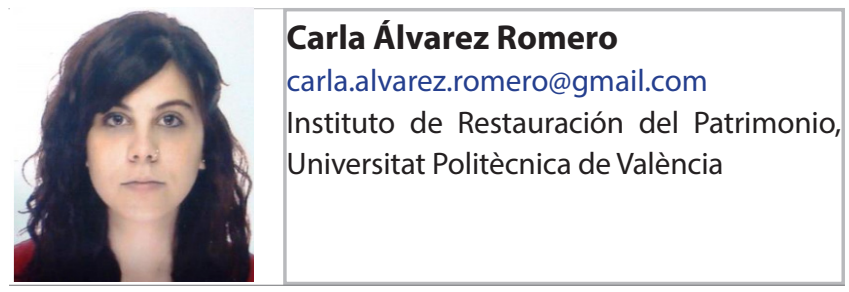

Licenciada en Historia con la intensificación en Arqueología y Prehistoria por la Universidad Autónoma de Madrid en 2012. En 2014 acaba sus estudios de postgrado realizando el Máster de Conservación y Restauración de Bienes Culturales en la Universitat Politècnica de València (UPV) y desde 2015 se encuentra realizando el Doctorado, inscrito en el programa de Conservación y Restauración de Bienes Culturales de la UPV con un contrato predoctoral para la formación de doctores del Ministerio de Economía y Competitividad. Sus investigaciones están centradas en el estudio arqueométrico y ciencia de la conservación de objetos arqueológicos, colaborando con instituciones españolas como el Museu de Prehistoria de València y el Museo Nacional de Arqueología Subacuática, e instituciones extranjeras como el Museo Nacional en Cracovia, Polonia, donde realizó una estancia de investigación. El desarrollo de esta actividad ha dado lugar a la publicación de cinco artículos en revistas indexadas, dos artículos en revistas no indexadas y cinco publicaciones en congresos, así como a la participación en congresos de ámbito nacional e internacional. También ha colaborado en tareas docentes en el Departamento de Conservación y Restauración de Bienes Culturales de la UPV durante varios cursos académicos.

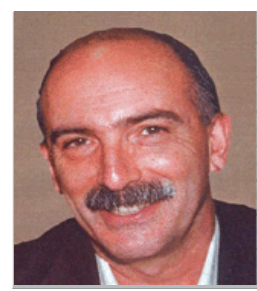

\section{Antonio Doménech Carbó}

antonio.domenech@uv.es

Departamento de Química Analítica,

Universitat de València

Doctorado en Ciencias Químicas por la Universitat de València. Estudi General en 1989, desde 1980 ha sido catedrático de Bachillerato compaginando este trabajo con el de profesor asociado desde 1993 hasta 2001 en que pasa a profesor titular y posteriormente, en 2010 catedrático de Análisis Químico en el Departamento de Química Analítica de la Universitat de València. En su trayectoria académica universitaria que supera los 25 años ha publicado cerca de 300 artículos, la mayoría de ellos en revistas indexadas y ha escrito varios libros por invitación para las editoriales Springer y Taylor and Francis sobre análisis electroquímico de bienes culturales. Es topical editor de la revista Journal of Solid State Electrochemistry y miembro del editorial board de la revista didáctica ChemTexts. Ha dirigido 7 tesis doctorales y numerosos proyectos de investigación competitivos de ámbito regional y nacional.

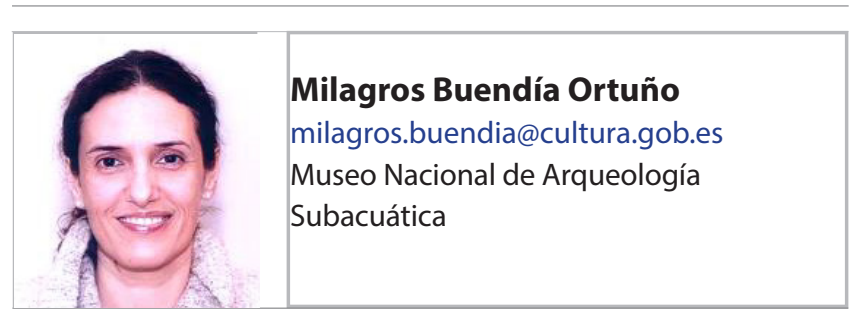

Doctora en Conservación y Restauración de Bienes Culturales por la Universitat Politècnica de València. Desde su licenciatura en 1996, amplía su formación en conservación de materiales arqueológicos con distintas estancias tanto en España como en el extranjero (Italia, Rusia o Guatemala). Su actividad profesional se ha centrado en la conservación y restauración de material arqueológico y ha desempeñado su trabajo para empresas privadas, organismos e instituciones públicas y en diversos museos como el Museu de Prehistòria de València y los Museos Arqueológicos de Murcia, Lorca, Jumilla, Mula o Sagunto. Desde 2003 es conservadora-restauradora del Museo Nacional de Arqueología Subacuática de Cartagena, y de su trayectoria en el centro destacan la participación en el Proyecto Museográfico (2006-2008) del museo en su nueva sede, la implementación del Programa de Conservación en intervenciones arqueológicas subacuáticas (2007-2011 Bajo de la Campana, Mazarrón, Punta de Algas), la aplicación del programa de conservación preventiva 
de elementos de la exposición permanente y colección de reserva y la conservación y restauración del conjunto monetario de la Fragata Nuestra Señora de las Mercedes. Ha participado como docente en cursos, Máster y Posgrados sobre conservación de patrimonio arqueológico en España y Guatemala. Es autora de artículos sobre la conservación de materiales arqueológicos de procedencia subacuática publicados en revistas especializadas, así como ponencias en diversos congresos y jornadas. Su labor de investigación se centra, desde 2007, en el marfil de procedencia subacuática, las defensas de elefante del pecio fenicio del Bajo de la Campana, San Javier (Murcia).

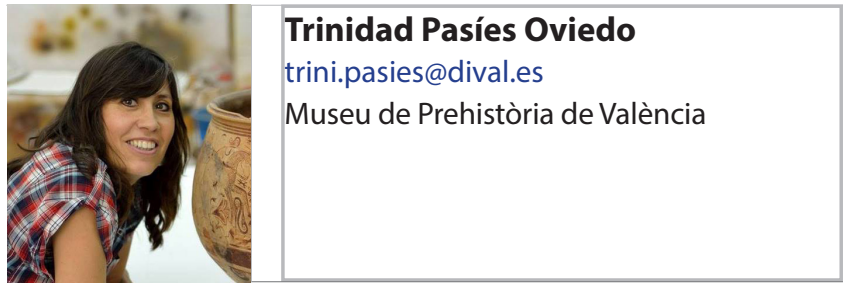

Restauradora del Museo de Prehistoria de Valencia e investigadora dentro del Servicio de Investigación Prehistórica de la Diputación de Valencia desde 2005. Licenciada en BBAA con la especialidad de restauración en 1992. Amplía su formación con estancias en centros internacionales de Italia, Guatemala, Francia, Turquía o Grecia. Se doctora en 2004 y presenta su tesis doctoral sobre la conservación de mosaicos romanos, publicada por la Universidad Politécnica de Valencia (UPV). Ha dirigido numerosas actuaciones de conservación y restauración arqueológica y ha colaborado con distintas instituciones nacionales e internacionales en proyectos de intervención. Relevante es su labor docente en cursos de especialización desde 1996, y entre 2017 y 2019 como profesora asociada del Dpto de Conservación y Restauración de la UPV. Su labor de investigación se refleja en numerosas publicaciones, impartiendo conferencias y como investigadora de proyectos $\mathrm{I}+\mathrm{D}+\mathrm{i}$.

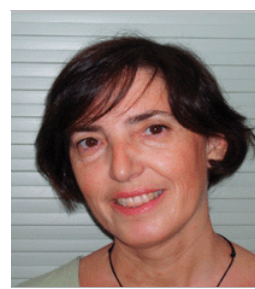

\section{María Teresa Doménech Carbó}

tdomenec@crbc.upv.es

Instituto de Restauración del Patrimonio,

Universitat Politècnica de València

General en 1989, desde 1984 hasta 1990 ha sido profesora agregada y catedrática de Bachillerato y desde 1990 es profesora de Análisis Químico de Patrimonio Cultural en la Universitat Politécnica de València (UPV) alcanzando la condición de catedrática en 1999, desde 2005 hasta 2016 ha dirigido el Instituto Universitario de Restauración del Patrimonio de la UPV (IRP). En su trayectoria académica universitaria que supera los 25 años ha publicado cerca de 200 artículos, la mayoría de ellos en revistas indexadas y ha escrito dos libros por invitación para las editoriales Springer y Síntesis sobre análisis químico de bienes culturales. También ha dirigido 19 tesis doctorales cuatro de las cuales han recibido Premios Extraordinarios a nivel Nacional y de la UPV y durante su mandato en el IRP ha dirigido la edición de la revista Arché del IRP. Ha coordinado sucesivos programas de doctorado ofertados por el Departamento de Conservación y Restauración de Bienes Culturales de la UPV. Finalmente cabe destacar que ha dirigido numerosos proyectos de investigación competitivos de ámbito regional, nacional y de la Comisión Europea y ha participado y dirigido un número muy elevado de convenios y contratos de I+D.

Artículo enviado el 04/09/2019 Artículo aceptado el 08/10/2019 